WellBeing International

WBI Studies Repository

$1-2004$

\title{
Trials, Tribulations, and Trends in Tumor Modeling in Mice
}

JoAnn C. L. Schuh

Applied Veterinary Pathobiology

Follow this and additional works at: https://www.wellbeingintlstudiesrepository.org/toxramres

Part of the Animal Experimentation and Research Commons, Animal Studies Commons, and the Other Medical Sciences Commons

\section{Recommended Citation}

Schuh, J. C. (2004). Trials, tribulations, and trends in tumor modeling in mice. Toxicologic pathology, 32(1_suppl), 53-66. DOI: https://doi.org/10.1080/01926230490424770

This material is brought to you for free and open access by WellBeing International. It has been accepted for inclusion by an authorized administrator of the WBI Studies Repository. For more information, please contact wbisr-info@wellbeingintl.org.

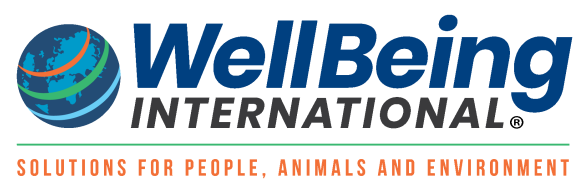




\title{
Trials, Tribulations, and Trends in Tumor Modeling in Mice
}

\author{
JOANN C. L. SCHUH \\ Applied Veterinary Pathobiology, Bainbridge Island, Washington 98110-3663, USA
}

\begin{abstract}
Selection of mouse models of cancer is often based simply on availability of a mouse strain and a known compatible tumor. Frequently this results in use of tumor models long on history but short on homology and quality control. Other factors including genetics, sex, immunological status, method and site of tumor implantation, technical competence, biological activity of the tumor, protocol sequence and timing, and selection of endpoints interact to produce outcomes in tumor models. Common reliance on survival and tumor burden data in a single mouse model often skews expectations towards high remission and cure rates; a finding seldom duplicated in clinical trials. Inherent limitations of tumor models coupled with the advent of new therapeutic targets reinforce need for careful attention to design, conduct, and stringent selection of in vivo and ex vivo endpoints. Preclinical efficacy testing for anti-tumor therapies should progress through a series of models of increasing sophistication that includes incorporation of genetically engineered animals, and orthotopic and combination therapy models. Pharmacology and safety testing in tumor-bearing animals may also help to improve predictive value of these models for clinical efficacy. Trends in bioinformatics, genetic refinements, and specialized imaging techniques are helping to maintain mice as the most scientifically and economically powerful model of malignant neoplasms.
\end{abstract}

Keywords. Preclinical efficacy testing; tumor models; study design; xenograft; orthotopic tumors; genetically engineered mice; bioinformatics; bioimaging.

\section{INTRODUCTION}

Malignant neoplasms rank second as the leading cause of death in the United States and ranked first in those aged 45-74 (Anderson, 2002). As a result, anti-cancer therapies are a frequent focus for startup companies and represent major therapeutic classes for pharmaceutical, biopharmaceutical, medical device and drug delivery manufacturers. Despite the effort applied to cancer targets, the number of successful new therapies for treating human malignancies is discouragingly low. This is surprising in that many trials are now conducted using novel agents with specificity for molecular pathways and cellular components rather than broad targeting of chemotherapy and radiation to normal and neoplastic cells. Failures in clinical trials are multifactorial with lack of efficacy an important cause. Conversely, modulating and curing experimental cancer in mice is a relatively easy process. Many commonly used mouse models of neoplasia have proven to be biased towards false positive results and preclinical studies have not accurately predicted clinical responses. Therefore, unconditional acceptance of limited data from mouse models has to be avoided to prevent premature movement of development programs into clinical testing. Increasingly, the plethora of novel strategies undergoing testing requires greater attention to proper design and conduct of preclinical efficacy studies. Rationale design of preclinical efficacy studies requires understanding the biology of tumors and implantation techniques, selection of in vivo and ex vivo endpoints, and a willingness to integrate new and often costly testing strategies that more appropriately mimic the biology of human neoplasms.

Address correspondence to: JoAnn C. L. Schuh, Applied Veterinary Pathobiology, 1752 Lewis Place NW, Bainbridge Island, Washington 98110-3663, USA; e-mail: schuhj@bainbridge.net

\section{BIOMEDICAL MODELS OF NEOPLASIA FOR PRECLINICAL TESTING}

\section{Spontaneous and Environmental Carcinogenesis Models}

Historically, spontaneous, chemical, ultraviolet (UV), oncogene, and viral infection models helped to define many aspects of carcinogenesis (Harrison, 2002) and therapeutic intervention (Boone et al., 1992) and helped to promote development of inbred strains of mice (Corbett et al., 2002). Despite the significance of spontaneous and environmental models to biomedical research, the long latency of most of these models makes them impractical for most preclinical studies of tumor modulation. Spontaneous, chemical and UV and viral infected or transformed tumors are of greatest importance as the source of many cells lines used for in vitro studies and in vivo transplantation models.

\section{Transplantation Models}

There are many immortalized cell lines of human and murine origin available from commercial sources and privately held by research organizations that have been tested for tumorigenicity in mice (Giard et al., 1973; Gershwin et al., 1977; Fogh et al., 1977; Trainer et al., 1988). In addition to availability, these tumorigenic cell lines are generally easy to maintain, selectable for unique mutations in vitro and backed by numerous publications on in vivo behavior in immunodeficient (nude, beige, nude/beige, C.B -17 severe combined immunodeficient [SCID], nonobese diabetic [NOD]/SCID), immunosuppressed (thymectomized or corticosteroid treated), humanized (hu)-SCID or hu-NOD/SCID and immunocompetent strains of mice. However, quality control is an issue. Many cell lines have undocumented source and passage histories, poorly characterized receptor and oncogene expression and cellular secretions, and inconsistent designations in publications. Features that make these tumor lines suitable for transplantation may affect experimental design 
because of the need for specific mouse strains, sex specificity, and altered host immunity. Furthermore, spontaneous mutations in vitro that allow selection of tumor cell line subclones with unique behaviors can also result in point mutations that lead to changes in histomorphology, sensitivity, and behavior of these tumors in vivo. Dissociated solid tumors and fragments of tumors (explants) that retain histomorphology relationships of the tumor and associated stroma are also suitable for implantation (Gershwin et al., 1977). Tumor cells from cell lines and solid masses of both human and mouse origin may require handling as biohazardous material due to their histogenesis by viral transformation or inadvertent contamination (Hay, 1991; Nicklas et al., 1993). The literature on tumors that have been used in mice to model important therapeutic targets in humans is vast. Due to the rapidly changing nature of biomedical research, a thorough and current literature search is warranted prior to selecting the most appropriate models for any therapeutic development program. A selection of representative mouse models (transplantation and genomic-based) for malignant neoplasms causing death in humans is provided in Table 1.

Criteria other than historical usage, and availability of the tumor line and a suitable mouse host need to be considered when testing efficacy of tumor modulation with therapeutics (Skipper, 1968; Huseby, 1969; Klausner, 1999). Even with genetically engineered models, multistep progression and clonal derivation of tumors in humans are difficult to model in mice. Therefore, foibles of these models need to be understood to prevent overinterpretation of positive or negative results.

\section{Considerations in Selecting Tumor Models in Mice}

It is well recognized that our understanding of modeling of tumor biology and therapeutic intervention is constrained by many factors (Siemann, 1987; Rew, 2000a; Rew, 2000b). However, validation studies of these model systems for their ability to adequately predict therapeutic responses in patients have been rare (Hann and Balmain, 2001). Consequently, design and interpretation of preclinical studies for tumor modeling must be undertaken carefully.

\section{Study Design}

Candidate anti-tumor agents can be identified and selected using a broad panel of in vivo tumors (Atassi et al., 1988) but false positive and negative results may occur due to incompatible host-tumor-therapeutic interactions or technical incompetence. In efficacy studies, greater depth needs to be achieved through evaluation of at least several subtypes of the tumor representative of the clinical target, and through use of different models systems in mice (transplantation, genetically engineered, and orthotopic models) as well as use of models in other appropriate species. Conduct of animal studies that mimic expected exposure, scheduling, and duration of therapeutic and posttreatment periods of clinical studies are valuable designs prior to initiating clinical trials. Optimization of therapeutic dose and schedule through pharmacokinetic studies are also important early procedures that should be evaluated in one or more model systems. Efficacy studies should also incorporate histopathology endpoints to confirm expected therapeutic target and to help refine dose scheduling relative to growth and cell loss fractions.

Investigators need to be aware that many historical and commonly used model systems in mice were originally established and optimized for use in mechanistic studies (Burger, 2000). Conduct of efficacy testing in such systems has not been optimized and inadvertent selection of systems with excess curability, spontaneous regressions or failure to establish adequate tumor burden (Corbett et al., 2002) can lead to overly optimistic projections of clinical success. Bias in the selection of the model(s) may also arise from experience, knowledge base and objectives of the investigator. Whereas pharmacologists, immunobiologists or cell biologists may consider direct intratumoral injection of therapeutics acceptable, needle tracks and pressure-induced necrosis (compartment syndrome) may interfere with adequate evaluation of such models by a histopathologist. Conversely, intratumoral administration of light activated substances is a common and appropriate route for photodynamic therapy of tumors (Casas et al., 1999). Design of efficacy studies for combination protocols is often difficult. However, such studies can provide important efficacy data for the transition between novel therapies and standard treatment practices that may

TABLE 1.-Rank order of deaths due to malignant neoplasms in the United States in 2001 (Arias and Smith, 2003) and selected published reviews on applicable mouse models of these neoplasms.

\begin{tabular}{rlrl}
\hline \hline Rank & Malignant Neoplasms & Cases & \multicolumn{1}{c}{ Selected Mouse Models } \\
\hline 1 & Lung-trachea & 156,005 & Tuveson and Jacks, 1999; Malkinson, 2001; Liu and Johnston, 2002 \\
2 & Colon-rectum & 56,799 & Heyer et al., 1999; Kobaek-Larsen et al., 2000; Horig et al., 2001; Boivin et al., 2003 \\
3 & Lymphoid-hematopoietic & 56,350 & Dykes and Waud, 2002; Uckun and Sensel, 2002; Vanderkerken et al., 2003 \\
4 & Breast & 41,844 & Hutchinson and Muller, 2000; Cardiff, 2001; Rosner et al., 2002; Clarke, 2002 \\
5 & Prostate & 30,714 & Royal et al., 1996; Navone et al., 1999; Abate-Shen and Shen, 2002; Nyska et al., 2002 \\
6 & Pancreas & 29,723 & Fu et al., 1992; Hotz et al., 2000; Standop et al., 2001; Bardeesy et al., 2001 \\
7 & Ovary & 14,361 & Rahman et al., 1998; Rahman and Huhtaniemi, 2001; Orsulic et al., 2002 \\
8 & Liver & 13,263 & Fausto, 1999; Feitelson and Larkin, 2001 \\
9 & Brain-meninges & 12,567 & Holland, 2001; Reilly and Jacks, 2001; Begemann et al., 2002; Gutmann et al., 2003 \\
10 & Esophagus & 12,509 & Opitz et al., 2002 \\
11 & Stomach & 12,340 & Furukawa et al., 1993b \\
12 & Bladder & 12,115 & Eto et al., 2000; Bonfil et al., 2002 \\
13 & Kidney & 12,084 & Naito et al., 1987b; An et al., 1999; Hillman, 2002 \\
14 & Oral & 7,638 & Waters et al., 1998; Myers et al., 2002 \\
15 & Skin & 7,543 & Alvarez, 2002; Eccles, 2002; Carson III and Walker, 2002 \\
16 & Uterus & 6,835 & Couse et al., 1997; Keshavarzi et al., 2002 \\
17 & Cervix & 4,064 & Herber et al., 1996 \\
18 & Larynx & Chen et al., 2001; Kennel et al., 2002 \\
\hline
\end{tabular}


include a combination of surgery, chemotherapy or radiation, and other supportive therapies (Bogden et al., 1974; Corbett et al., 1979). In designing tumor model systems, investigators must guard against template designs that ignore inherent differences in model systems, and in using insufficient animals per group. This is particularly important in investigational new drug (IND) enabling studies where more animals per group and few groups may be required to adequately control for variation in tumor burden and therapeutic responses. Consultation with a biostatistician to assist in determination of sample size appropriate to each model system is highly recommended.

\section{Context of the Study and Available Resources}

Therapeutic intervention conducted in tumor-bearing animals may occur as proof of principal studies for discovery, target validation, and in vivo pharmacology, or as investigations for therapeutic efficacy, safety, and interactions. These types of studies often need to be designed and conducted differently than studies focusing on mechanistic studies. Additionally, an available supply of suitable strains of mice and investigators capable of providing necessary manipulations (injections, surgery, polytherapy, evaluations, and pathology services) may materially affect both quantity and quality of data that can be generated from selected models.

\section{Lack of Quality Control}

Investigators using cell lines should develop and maintain in-house databases that allow ready access to known features for tumor cell lines in their collections. A minimum list might include all applicable information that defines origin (human or animal), sex and strain of original host, treatment history (particularly human lines), name and subclone of the tumor line, source (commercial or private), passage history of all aliquots, species, strain and sex and routes susceptible to implanted tumors, in vitro and in vivo growth characteristics, growth rate to maximum humanely accepted and lethal sizes, histomorphological characteristics, metastatic potential and method, immunogenicity, receptor and oncogene expression, cellular products, microbiological screening history, biohazard potential (generally viral) and unique characteristics. This information is invaluable for preventing and investigating problems such as implantation failures, excess curability, microbial contamination, mislabeled or cross-contaminated stocks, and alterations in histomorphology and behavior that may arise from haphazard use of cell lines (Corbett et al., 2002). With rare exception (Rosner et al., 2002), thorough characterization of comparative histology of tumor models using authenticated stocks has not been adequate. Additionally, microbial and cross-species contamination of cell lines has lead to erroneous conclusions in tumor biology (Moseley et al., 2003; Drexler et al., 2003). These problems are compounded by lack of source and passage history information reported by most laboratories conducting either mechanistic or efficacy studies. This is not a trivial problem, as the histomorphology and behavior of tumors grown from stocks in different laboratories may eventually differ from historical photomicrographs and behavior descriptions of the original tumor and its cell line (Schuh, unpublished data). Although the original passage history may not be known, investigators should strive to use contaminant free tumor lines of a con- sistent number of passages from an authenticated stock for preclinical testing. In addition to providing a known in-house passage history, testing from a stock provides a baseline and helps to reduce the potential for point mutations that may cause inter-study variation or erroneous test results.

\section{Paraneoplastic Syndromes}

Paraneoplastic syndromes typically result in clinical manifestations of altered physiological responses to autochthonous (spontaneous) neoplasms. These syndromes in mouse models of neoplasia have been seldom described (Liebelt et al., 1974) even though they exist. This oversight is brought on by the focused and short-term nature of most studies. Unlike safety studies where a complete set of tissues are collected and a clinical pathology examination conducted, efficacy studies are often completed without benefit of histopathology and clinical pathology examinations. This type of study design neglects important interactions of the host with tumor receptor expression and secretions produced by tumor cells or by stimulation of host cells by the tumor. Paraneoplastic syndromes include extramedullary hematopoiesis, bone marrow hyperplasia, peripheral granulocytosis and leukocytosis (leukemoid reactions), thrombocytosis, anemia, altered lipid metabolism, hypercalcemia of malignancy, hypoglycemia, cachexia and organomegaly in nontumor-bearing tissues (Liebelt et al., 1974; Castillo et al., 1982; Yoneda et al., 1991; Tanaka et al., 1996; Diament et al., 1998, Schuh, unpublished data). Paraneoplastic syndromes represent potential models for similar syndromes in humans but causation are poorly characterized and effects of these syndromes on pharmacology, safety, and efficacy studies using experimental tumors are unknown.

\section{Transplantation Protocols: Sites of Implantation Can Affect Study Outcome}

Autogeneic or autochthonous tumors are seldom practical for tumor modeling for therapeutic intervention. Most transplantable tumors are placed heterotopically (ectopically) in syngeneic (same species, genetically identical), allogeneic (same species, genetically different) or xenogeneic (different species and genetics) host systems. Tumor lines in use have been specifically selected for mutations that allow heterotopic growth in mice. Although these tumors will grow and respond to therapeutics, heterotopic sites are not ideal and selection of the transplantation site may modulate tumor growth (Naito et al., 1987a; Corbett et al., 2002) and success of therapeutic intervention (Averbook et al., 2002).

Subcutaneous (SQ) and less frequently intradermal areas are used for primary tumors for reasons of accessibility, lack of distress and interference with mobility in mice, and visibility for monitoring. Generally, SQ refers to placement by injection or surgical implantation in the flank, a region referring to the posterior lateral abdominal quadrant. Some investigators erroneously include the hindlimb, back and axillary region in their description of the flank. Placement is generally done in fat and mammary gland tissues near popliteal, inguinal or accessory axillary lymph nodes. Despite the common use of SQ sites, it is important to note that even large tumors rarely, if ever, metastasize after implantation in this site (Gershwin et al., 1977; Eccles, 2002). Implantation in the hindlimb (including popliteal lymph node 
fat) is sometimes considered superior to placement near body cavities for improved visualization and avoidance of accidental intra-peritoneal or -thoracic implantation. Rarely, tumors may not be viable after SQ implantation and other sites may be required. Implantation of tumors into footpads is generally not acceptable for humane considerations (UKCCCR, 1998; Wallace, 2000). Intramuscular implantation is not common as cell lines and tumor explants may not grow well in muscle compared to SQ, leg mobility is restricted by large masses, expansion space is limited, measurements with calipers are more difficult and this site appears to be more prone to selfmutilation and a target for cage mate aggression. Fat pads other than classic SQ sites, including retroperitoneal, epididymal, intrascapular and mediastinal/thymic sites are also valuable locations for injection and surgical implantation to provide a highly vascular milieu that appears to assist in establishment of xenogeneic tumors. A comparison of tumor viability in brown fat in interscapular areas, compared to the predominate white fat in other fat pads does not appear to have been made.

Primary and sometimes metastatic models are also established by direct surgical or percutaneous intra-organ injections into spleen, liver, lymph nodes, mammary gland, prostate, base of the tongue (head and neck carcinoma), intraluminal (bronchial, urinary bladder, thorax), cecal wall implantation (colorectal metastases), and kidney capsule. Injection into brain and eye are often not considered acceptable by institutional animal care and use committees (IACUC) (UKCCCR, 1998; Wallace, 2000).

Metastatic and sometimes primary tumor models are created by intravenous, intracardiac (ventricle), intraosseous injections or intravascular injections proximal to organs (e.g., portal vein for liver neoplasms). Despite careful preparation to reduce cell clumps and to inject slowly, such tumors are embolic and may grow in unintended sites. Most tumors show selective tissue tropisms, but tumors with broad tropism (e.g., lymphoma/leukemia) may grow within all tissues and result in large unmonitorable tumor burdens (Schuh, unpublished data). Investigators rarely evaluate tissues for metastases outside of their specific area of interest (most often lung and bone) so that characterization of additional tumor burdens and thromboembolism of tumor cells on validity of these tumor models is lacking. Intraperitoneal injections of tumors, once a common route for leukemias and metastatic models, have humane considerations that need to be considered (UKCCCR, 1998; Wallace, 2000).

Implantation techniques must be practiced, as accidental injection into muscle masses or visceral cavities, and postsurgical inflammation can cause intra-study variability and lack of interstudy reproducibility. Migration through SQ tissues or leakage of cell suspensions is generally not an issue with proper technique and minimal volumes injected with a small gauge needle. Interstudy reproducibility of implanted tumor burdens may be affected by extent of cell separation, particularly for disruption of in vitro cultures or solid tumors (An et al., 1999). In some efficacy studies, surgical implantation of hollow fibers (Sadar et al., 2002), matrigel and discs (Eccles, 2002), polymers (Righi et al., 2003), liposomes (Kunstfeld et al., 2003), and transparent windows (Dellian et al., 1996; Li et al., 2000; Jain et al., 2002) can provide a tightly contained tumor environment to optimize reproducibility for certain endpoints such as angiogenesis. Inflammation and interference with tumor biology must be considered when utilizing surgically implanted devices for containment of tumor masses.

\section{Other Host-Tumor-Therapeutic Interactions}

Differences in tumor burden potential, angiogenic and therapeutic response have been shown to be due to differences in strains of mice tested (Naito et al., 1987b), primary implantation site and interval between tumor implantation and therapeutic manipulations (Wilmanns et al., 1992; Chakrabarty et al., 1994; Averbook et al., 2002; Monsky et al., 2002), and metastatic microenvironments (Averbook et al., 2002; Seki et al., 2003). For xenogeneic and syngeneic tumors that require immunodeficient mice, differences in immunological defects between these strains should be understood. Similarly, immunogenicity of tumors in immunocompetent hosts may be an important modifying factor. Other factors that can affect tumor growth in vivo include concurrent manipulations such as surgery, radiation or concurrent treatments that produce inflammation and inhibit establishment of tumor cells. Conversely, stress and seasonal effects may increase tumor burden and distribution (Giraldi et al., 2000). Finally, for long standing tumors, tumor-induced cachexia may suppress tumor growth and enhance efficacy (Laster et al., 1961; Chakrabarty et al., 1994; Mukherjee et al., 2002), similar to delays in tumor development found with intentional caloric restriction in rodents (Suttie et al., 2003). Therapeutic efficacy is also modulated through tissue specific and immunologic modifiers, and differences in drug metabolism and disposition (Gershwin et al., 1977; Naito et al., 1987a; Wilmanns et al., 1992; Averbook et al., 2002; Seki et al., 2003).

Specific strains of mice used for tumor models are usually matched to origin of the transplanted tumor. Where multiple tumor cell lines are available to model certain tumors, unique characteristics of these tumors such as host origin, oncogenes, receptors and secretions, and tumor stage may be an important consideration. However, these parameters are often difficult to match to comparable stages in humans (Harrison, 2002). With these limitations in available models, selection of or reporting only on tumors that are dramatically and positively affected by test therapeutics should be avoided. Testing therapeutic interventions on similar tumor types derived from multiple cell lines provides a test situation that partially addresses heterogeneity of tumors in humans. That some of these tumors may not be modulated by the test therapeutic should be expected, and these nonresponders should not be treated as preclinical failures or dismissed. Rather, both negative and positive tumor responses can provide investigators with a more realistic expectation of therapeutic potential in humans, and the totality of the response across several models provides superior insight into activity of therapeutics.

\section{ENDPOINTS AND EVALUATION CRITERIA FOR TUMOR MODELS IN VIVO}

Critical host-tumor-therapeutic interactions, doseresponse, treatment protocol design, and selection of endpoints interact to produce outcomes in tumor modeling (Skipper, 1990; Kerbel, 1999). The goal in clinical oncology is regulation to improve survival and quality of life, and 
to prevent recurrent disease rather than to cure/kill cancer (Schipper et al., 1995). More stringent criteria than curability of experimental tumors in mice need to be assessed to determine therapeutic efficacy. Counts of tumor bearing animals and measurement of tumor burden are the easiest and most frequently used outcomes of efficacy in preclinical studies. In reality, endpoints need to be matched to type of tumor (solid, leukemia or metastatic), context of the study, accessibility of the implantation site, type of implantation, and therapeutic class. Simplistic criteria used in mouse models do not match criteria of partial and complete responses used in clinical oncology, and they contribute to the conflicting opinions about the relevance and predictability of mouse models. Therefore, use of other metrics, and evaluations of angiogenesis, immunomodulation, metastases, and detailed histopathology need to be incorporated into most study designs for preclinical testing. Despite the technical difficulty, labor-intensive nature, and expense commonly cited as limitations for detailed examinations, the utility of mouse models is improved by multiple and appropriate endpoints (Table 2).

\section{In Vivo Endpoints}

Tumor growth inhibition studies where treatment is prophylactically administered before or on the day of tumor induction are not realistic for preclinical evaluation of clinical responses. Typically, preclinical efficacy studies utilize tumor growth delay in which tumors are induced by injection or surgical implantation and allowed to establish for a number of days prior to initiation of treatment. Solid tu- mors in accessible sites are amenable to a variety of metrics that are not applicable to primary and metastatic tumors of internal organs and hematologic neoplasms. A count of tumor-bearing animals assumes that nontumor-bearing animals represent tumor regression or cures. Spontaneous regressions, failure of tumors to become established or displaced tumor mass into adjacent body cavities may account for a small percentage of false cures. For this reason, tumor onset and progression should be monitored daily to ensure adequate and similar tumor masses prior to treatment and monitor onset of regression in each group. In models with log-phase tumor growth, animals can be randomized into treatment groups after a predictable period of development, usually 3-14 days. Conversely, less well-developed tumor models may require enrollment of individual animals into the study when the tumor burden reaches a minimum size. Such enrollment studies are difficult to evaluate. Allowing extra days for tumor growth may be as misleading as starting treatment on small tumor masses that have not established and show enhanced regression after onset of treatment. In vivo progression of tumor burden should be evaluated on a daily basis, excluding tumor free animals as they appear. Burden is commonly measured with calipers and volume estimated from measurement of two (length and width) dimensions (Corbett et al., 2002; Teicher, 2002). Estimates of tumor weight (length[ width $\left.^{2}\right] / 2$ ) using the typically inaccurate measurements derived from tumors of varying shapes and boundaries is not recommended. Tumor growth delay measures the difference in days for the mean or median tumors in test and control animals to reach a specific volume, usually

TABLE 2.-Endpoints to evaluate preclinical efficacy of tumor models in mice.

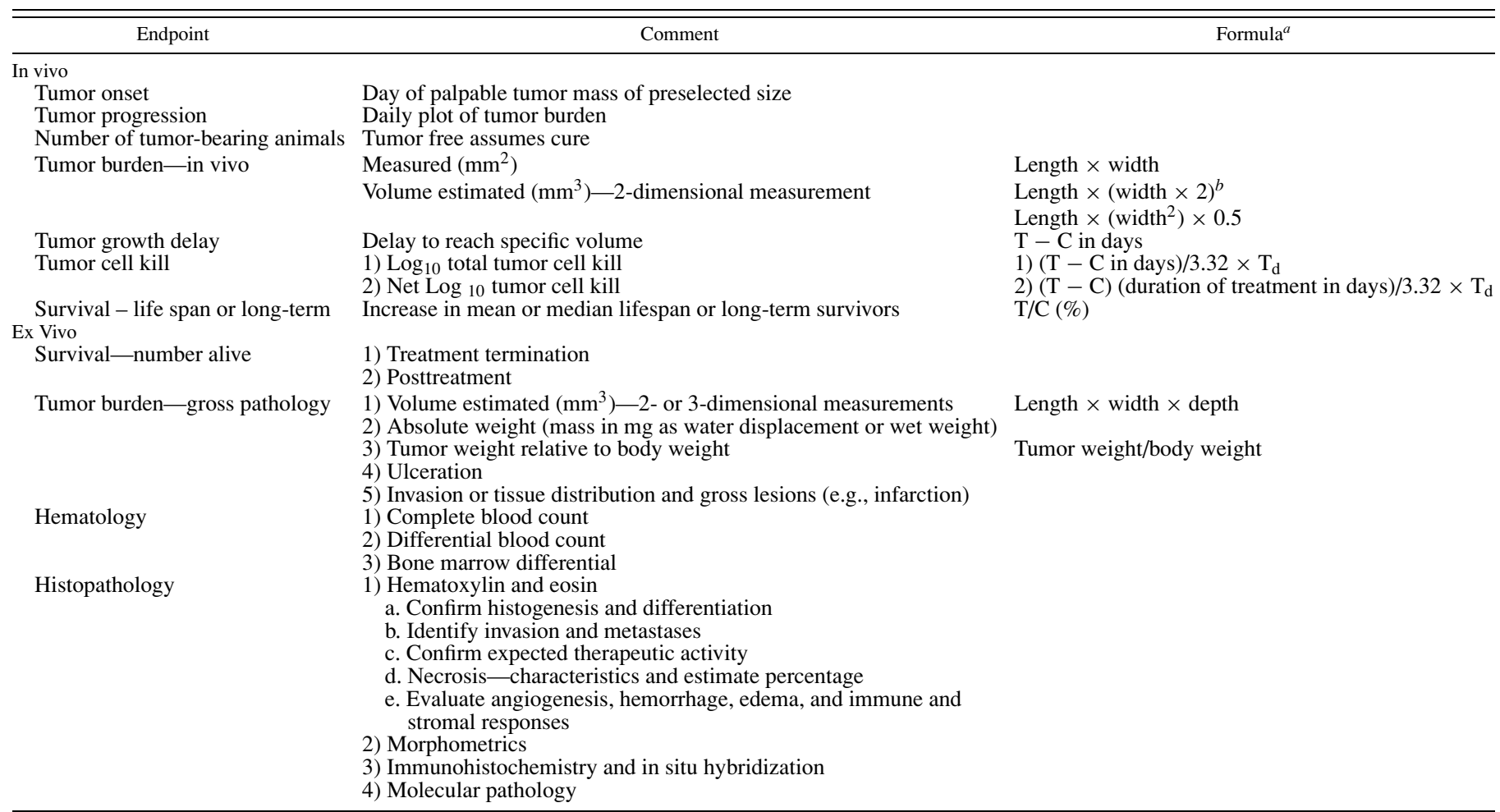

\footnotetext{
${ }^{a} \mathrm{~T}=$ test; $\mathrm{C}=$ control; $\mathrm{T}_{\mathrm{d}}=$ doubling time; $3.32=$ doublings to increase $1 \log _{10}$ unit.
}

${ }^{b}$ Formulas used for volume estimates vary. 
$0.5-1.0 \mathrm{~cm}^{3}$. This value has been suggested to mimic clinical endpoints and disease progression, but this measure is often incorrectly applied. A 50\% reduction in tumor mass as a measure of cytoreduction used to gauge clinical responsiveness is not equivalent to $50 \%$ inhibition of tumor growth commonly used as a measure of preclinical efficacy (Corbett et al., 2002; Teicher, 2002). Tumor cell kill (net and total) for leukemic or solid tumors requires tumor titration using 10-fold dilutions to determine doubling time, and comparison to tumor growth delay and duration of treatment. Despite the value and more exact nature of these determinations, extra time and additional test animals required generally result in infrequent use of these endpoints (Corbett et al., 1999; Harrison, 2002; Teicher, 2002). Survival data should not be mistaken for mortality, an unacceptable endpoint (UKCCCR, 1998; Wallace, 2000). An increase in percentage mean or median survival may be measured for the lifespan or in long-term survivors. Clinically, posttreatment survival is a valuable endpoint that evaluates treatment efficacy during and after treatment. Survival at study termination is inadequate due to the short duration of most assays and lack of posttreatment data. For many tumors, a log-linear growth cannot be assumed, and more importantly, regrowth of tumors post-treatment may escalate due to increased doubling times (Gunduz et al., 1979; Teicher, 2002). Retention of a subset of animals for several weeks after treatment ends may demonstrate a rapid regrowth of tumor at the efficacious dose that quickly parallels morbidity of controls and lower dose groups. In spite of a delay in tumor growth over the treatment period, a rebound effect post-treatment would be an indication of lower overall efficacy.

\section{Ex Vivo Endpoints}

At study termination, volume measurements similar to those performed in vivo can be made at gross pathology, but mass (water displacement) or absolute wet weight ex vivo is more exacting. Volume measurements at termination may show significant disparity from final in vivo measurements. Irregular shapes, small or multilobular masses and necrosis, edema, and hemorrhage all contribute to variation in estimates of tumor burden measurements. Relative tumor to body weight ratios are often useful to gauge therapeutic efficacy in slow growing tumors and when cachexia is present. The relative ratio can reduce or expand differences between controls and treated animals and is a valuable and easily obtained supplement to absolute tumor weight. Visualization and quantification of metastases is particularly difficult to monitor as multifocal and occult tumor burdens are frequent. Flooding of airways with India ink to highlight lung masses for counting, "bread loafing" of the target organ for metastatic counts and organ weight differences compared to controls are inexact measurements prone to intra- and inter-study variability. Such models are better served by tagged tumors and advanced imaging technologies. Gross pathology examination should evaluate presence or absence of ulceration, extent of intentional or inadvertent invasion, tissue distribution beyond the primary implant site, and identify other gross lesions. Accidental implantation of tumors into body cavities can skew results by partial growth of tumor at the intended site that responds to treatment, along with a large internal tumor burden that is unresponsive to treatment. Hematology (complete blood count and differential) and bone marrow differentials (smears or fluorescent activated cell sorting analysis) can provide data about paraneoplastic syndromes and toxicity. However, hematology and histopathology endpoints are often considered elective. Histologic screening of tumors is valuable to confirm histogenesis and state of differentiation of tumors for quality control and to identify and separate local invasion from metastasis. Characteristics of the tumor such as necrosis, angiogenesis, hemorrhage and immune cell and stromal responses should be monitored. More importantly, histology should confirm the expected activity and target of the therapeutic class. Novel therapeutics currently under development are driving the need for additional ex vivo studies such as morphometry to evaluate angiogenesis and apoptosis, immunohistochemistry, in situ hybridization and molecular pathology to evaluate changes in macromolecules, immunophenotypes and nucleic acids.

\section{Pharmacology and Safety Endpoints in Tumor-Bearing Animals}

Toxicokinetic (TK), and absorption, distribution, metabolism, and excretion (ADME) studies are generally performed early in drug discovery (Lin et al., 2003) and are often incorporated into anti-tumor protocols to determine dose and scheduling. Conversely, safety testing is almost exclusively performed in nontumor-bearing animals. Considering the altered homeostasis of most tumor-bearing animals and humans, safety in a tumor-bearing host should be considered to fully evaluate the therapeutic response and potential. Adverse events can be monitored using a standard safety protocol in tumor and a non-tumor-bearing mouse model, but tolerability of treatment is more difficult to monitor. Limited resources and economic restraints would not support conduct of a full safety program in tumor-bearing animals, but examination of a full panel of tissues from at least one model may be useful to identify adverse effects, modulation of paraneoplastic syndromes, and tolerability issues. Although safety information is generally collected in immunocompetent animals, use of immunodeficient strains may be a better predictor of TK/ADME and safety as a mimic of immune dysfunction after chemotherapy, radiation therapy, surgery (Wichmann et al., 2003), infections and paraneoplastic syndromes (Tanaka et al., 1996). A modified safety study can be incorporated into an efficacy study by collecting a complete or selected list of tissues from tumor-bearing animals and by including treated but non-tumor-bearing animals as additional controls. Although safety information in tumor-bearing animals may be incomplete, this data supplements efficacy, TK and ADME data and can provide needed redirection in dosage and scheduling for subsequent studies.

\section{Humane Considerations}

Therapeutic intervention trials may use both short-term and long-term tumor growth models depending on growth rate and aggressiveness of the tumor. Mortality should not be used as an endpoint. Commonly used endpoints such as tumor burden should be limited according to absolute values and relative to body weight. Therefore, careful monitoring and humane endpoints need to be developed in conjunction with the IACUC. Ulceration, tissue and body cavity distension, 
inanition, cachexia, anemia, increased intracranial pressure, self-mutilation, cannibalism, and metastases also contribute to premature death of study animals and may require a limited protocol or modified study design (UKCCCR, 1998; Wallace, 2000).

\section{TRENDS IN TUMOR MODELING}

\section{Bioinformatics and Mouse Models of Cancer}

The evolution of new mouse models of cancer is tightly bound to knowledge gained from sequencing of human and mouse genomes, and compilation and dissemination of this knowledge on the World Wide Web. Important databases for tumor modeling include the Mouse Tumor Biology Database at 〈http://tumor.informatics.jax.org ( $\mathrm{Naf}$ et al., 2002), databases accessible through the National Center of Biotechnology $\langle\mathrm{http}: / / w w w . n c b i . n l m . n i h . g o v\rangle$ including human and mouse genomes (Wheeler et al., 2003) and The Whole Mouse Catalog 〈http://www.rodentia.com/wmc/ $\rangle$.

\section{Technical Trends in Tumor Modeling}

Technical advances in tumor modeling have included use of skin fold and transparent windows (Dellian et al., 1996; Li et al., 2000; Jain et al., 2002), matrigel (Eccles, 2002), polymers (Righi et al., 2003), liposomes (Kunstfeld et al., 2003), chambers (Dvorak et al., 1987) and hollow fibers (Sadar et al., 2002) to contain tumor growth and monitor angiogenesis. Ex vivo perfusion (Kristjansen, 2002) and intravital microscopy are providing insights into drug metabolism, angiogenesis and in situ tumor responses (Jain et al., 2002).

Improved imaging of tumors has revolutionized noninvasive monitoring of distribution, growth, metastasis and morphometrics of tumor models in mice. Available systems include micro positron electromagnetic imaging (Ray et al., 2003; Yang et al., 2003), magnetic resonance imaging (Berr et al., 2003; Nelson et al., 2003), in situ visualization of primary and metastatic tumors and occult metastases (Menon and Teicher, 2002), using improved fluorochromes (Rosenberg et al., 2003) and quantum dots (Watson et al., 2003), green fluorescent protein (GFP) (Hoffman, 2002), and luciferase (Edinger et al., 1999; Burgos et al., 2003). Improved fluorochromes, GFP, and LacZ (Kruger et al., 1999; Culp et al., 2001) are also retained within tissues and allow microscopic evaluation by fluorescent microscopy and histochemical or immunohistochemical staining of tumor tissues. Laser capture microdissection is a proven technology for identification of genetic heterogeneity of tumors that continues to expand our knowledge of tumor biology (Culp et al., 2001; Hoon et al., 2002). Specialized microscopy using confocal (Paddock, 1999) and deconvolution (Maierhofer et al., 2003) microscopes are also positioned to provide optical sectioning for identification of 3-dimensional distribution of tumor elements and drug distribution within tumors (Manivasager et al., 2002). While many of these improvements are expensive and impractical for incorporation into preclinical studies, selective use of advanced technologies in drug discovery, pharmacology and preclinical studies can provide minimally invasive and detailed information about host-tumor-therapeutic interactions in vivo at multiple timepoints.

\section{Biological Trends: Genetically Engineered Mice}

Neoplastic transformation and progression requires a series of genetic alterations that disrupt the balance of cellular mechanisms involving cellular growth and deletion. Mice have played an important role in defining the genetic mechanisms of carcinogenesis. Thus, it is no surprise that genetically engineered mice (GEM) are beginning to take their rightful place as models that show accelerated tumor development and recapitulate the genetics and behavior of human cancer states and cancer resistance (Mickisch et al., 1991; Pitot, 2001; Klatt and Serrano, 2003). Selected target genetic events allow creation of gene-driven gain of function transgenic, loss of function deletion (Reilly and Jacks, 2001; Meuwissen et al., 2001; Resor et al., 2001; Balmain, 2002; Jackson-Grusby, 2002; Herzig and Christofori, 2002; Tuveson and Jacks, 2002; van Dyke and Jacks, 2002), conditional function (Jonkers and Berns, 2002), clones (Rideout III et al., 2000) and phenotypically-driven $N$-ethyl$N$-nitrosourea mutants (Justice et al., 1999; Balmain, 2002). Although genetically engineered mice have been advocated for preclinical testing (Feitelson and Larkin, 2001; Horig et al., 2001), problems associated with these models include discordance in etiology and histogenesis between human and mouse tumors, multifocal tumors due to multi-tissue deletions or promotor promiscuity, failure to metastasize, variable penetrance of transgenes, long latency (Rosenberg and Bortner, 1999; Moore and Nagle, 2000), limited availability, lack of extensive historical pathology databases for founder strains (FVB, 129 strains, BALB/c), and costs and effort in creating and maintaining specialized GEM animal colonies. Regardless, the ability to use GEM to genetically, anatomically, pathophysiologically and histologically mimic tumors found in humans is becoming a reality. As more logistical problems are overcome, these genomic-derived models will likely become more consistently incorporated into preclinical testing. Compared to transplantation models, GEM will be particularly useful to create tumor states that were previously difficult to model including nervous system (Gutmann et al., 2003), pancreas (Hotz et al., 2000; Bardeesy et al., 2001), lung (Tuveson and Jacks, 1999; Liu and Johnston, 2002), breast (Hutchinson and Muller, 2000), ovarian (Rahman et al., 1998; Rahman and Huhtaniemi, 2001; Orsulic et al., 2002), prostate (Sharma and Schreiber-Agus, 1999; Navone et al., 1999), oral (Opitz et al., 2002), liver (Fausto, 1999; Feitelson and Larkin, 2001; Koike, 2002), hematologic malignancies (Bernardi et al., 2002; Herzig and Christofori, 2002), pediatric tumors (Beltinger and Debatin, 2001; Houghton et al., 2002), gene-environment interactions (Hursting, 1997), and metastases (McClatchey, 1999; Herzig and Christofori, 2002), and to test interventional feasibility for novel therapeutics against bone metastasis (Fausto, 1999), cell adhesion dysfunction (Herzig and Christofori, 2002), telomere dysfunction (Goytisolo and Blasco, 2002; Artandi, 2002; Granger et al., 2002), ribosomal RNA modification (Ruggero et al., 2003), and DNA hypomethylation (Goodman and Watson, 2002; Gaudet et al., 2003). Despite these ongoing advances in model systems, disease states associated with tumors such as minimal residual disease (Teicher, 1997; Wetterwald et al., 2002), concurrent opportunistic infections, and treatments such as surgical debulking and combination 
therapy will continue to resist modeling in mice for practical and humane concerns.

\section{Biological Trends: Modified Immunodeficient Mice}

Nude (athymic) and C.B-17 SCID (T and B cell deficient mice) fail to reject engraftment with a variety of human and mouse tumor cells (Pettaway et al., 1996; Lapidot et al., 1997; Bankert et al., 2002; Giovanella, 2002; Uckun and Sensel, 2002) by virtue of their T and B cell defects. The presence of innate immunity, particularly natural killer (NK) cell activity is probably an important factor in limiting tumorigenesis and metastases in these models. The nude mutation results in a mouse that is $\mathrm{T}$ cell deficient and has $\mathrm{B}$ cell maturational defects, but with intact innate immunity including tumoricidal macrophages and an increase in NK cells. This mutation has been introduced into many mouse strains. Introduction of the beige mutation blocks NK and myeloid-derived cell activity and additional $\mathrm{B}$ cell defects result by crossing with the X-linked immunodeficiency mouse. The ChédiakHigashi syndrome (hypopigmentation, bleeding diathesis and recurrent bacterial infections) in mice or hybrids with the beige anomaly limits their usefulness in surgical, including orthotopic models (Clarke, 2002). The T and B cell deficient SCID mouse has been particularly amenable to further manipulation and modifications involving expanded immunodeficiencies and "humanization." These mice are useful for mechanistic studies and for evaluating anti-tumor therapies on human xenografts (Bankert et al., 2001). However, NK cell activity and the tendency of some SCID mice to become "leaky" and develop active T and B cells, and early onset lymphoproliferative diseases can be problematic. Introduction of the nonobese diabetic (NOD) mutation and recombination activating gene (Rag) deficiency are useful modifiers for the SCID mutation (Clarke, 2002; Eccles, 2002). The NOD mouse is a complex model of immune defects that includes autoimmune mediated type- 1 diabetes and sialitis, and Rag-1 and Rag- 2 null state produces a severe combined immunodeficiency. Combination of these mutations with SCID defects results in mice that are no longer leaky and NK cell activity is reduced while retaining the ability to support xenografts (Bankert et al., 2001).

SCID or NOD-SCID mice made chimeric with implanted human lymphoid tissues, peripheral blood cells or bone marrow cells are the most commonly used "humanized" mouse models. These models have been generated to provide surrogate human microenvironments and to test immunotherapies (Bankert et al., 2001). Anti-tumor responses in humanized mouse models have not been extensively validated and their use supplements rather than supplants other mouse models for antitumor testing.

\section{Biological Trends: Orthotopic Models}

Less than ideal growth and behavior of heterotopic implants has lead to development and characterization of surgical and cellular orthotopic implants (Manzotti et al., 1993). Both normal and neoplastic cells (individual or clusters) and histologically intact tissues, of fetal and adult origin can be used in syngeneic and xenogeneic orthotopic mouse systems. Normal tissues can be implanted and mice injected with tumor cells to produce an improved metastatic model, and using tumor cells with a reporter gene allows enhanced imaging capabilities. Implantation of tumor tissue into anatomically correct tissue for the histogenesis of the tumor (i.e., kidney tumor in kidney) rather than heterotopic implantation promotes improved tumor growth and metastases (Naito et al., 1987a, 1987b; Menon and Teicher, 2002). Orthotopic models also allow correlation of experimental responses with the original tumor in the host (Steel, 1987).

Although orthotopic models have been utilized for many years, the need for surgical manipulation in many of the models and need for a fresh source of human tissues (normal or neoplastic) adds to the difficulty and expense of this type of implantation. Regardless, orthotopic models provide a useful model for establishing tumors previously difficult to model (Fu et al., 1992; Furukawa et al., 1993a, 1993b; An et al., 1999; Myers et al., 2002) and can be used alone or in combination with humanized mice (Klausner, 1999; Kunstfeld et al., 2003). Orthotopic models allow efficacy testing for tumor inhibition and metastases (Menon and Teicher, 2002; Zhang et al., 2002; Boyd et al., 2003) and appear to be better predictors of clinical success than heterotopic models (Kuo et al., 1993; Manzotti et al., 1993; Killion et al., 1999; Hoffman, 1999; Bloomston et al., 2002).

\section{Other Animal Models for Preclinical Efficacy Studies}

Their size, fecundity, ease of handling, relatively economical production and care (excluding genetically altered mice), strain selection, and short gestation backed by massive databases of susceptibilities, genetics, immunology, physiology, pathology, and microbiology make mice an ideal candidate for tumor biology and preclinical efficacy studies. Rats and hamsters are also useful for biological and therapeutic modulation because of their propensity to develop a variety of spontaneous tumors, their amenability to tumor implantation, availability of cell lines (Schwartz and Gu, 2002; Thompson and Sporn, 2002), and recent development of genetically altered rats lacking suppressor genes linked to breast and ovarian cancer (Zan et al., 2003). Beyond rodents, a limited number of spontaneous neoplasms in companion and domestic animals (Vail and MacEwen, 1997; Knapp and Waters, 1997; Dewhirst et al., 2002) and other species including genetically altered fish (Vanchieri, 2001; Spitsbergen and Kent, 2003) also have some potential value in preclinical efficacy testing. Dogs, particularly older males provide a very useful model of prostatic disease (Waters and Bostwick, 1997; Waters et al., 1998; Strandberg, 2000) and dogs larger than purpose-bred Beagles are often the only relevant model to test medical devices or device/drug combinations for anti-tumor applications.

\section{TOWARDS AN IDEAL PRECLINICAL EFFICACY TESTING PROGRAM}

In order to transition into clinical trials, regulatory agencies must be provided with evidence that the new therapeutic has an improved safety and/or efficacy profile compared to current therapies. Therefore, selection of tumor models in mice is best approached by using specific criteria that match biologic (multistage, clonal, progression, histomorphology, and metastasis), genetic (multiple mutations, altered chromosomes and cell signaling, genetic expression profile and susceptibility), inductive etiology (chemicals, UV light, diet, hormones and viral), immunogenicity and therapeutic 


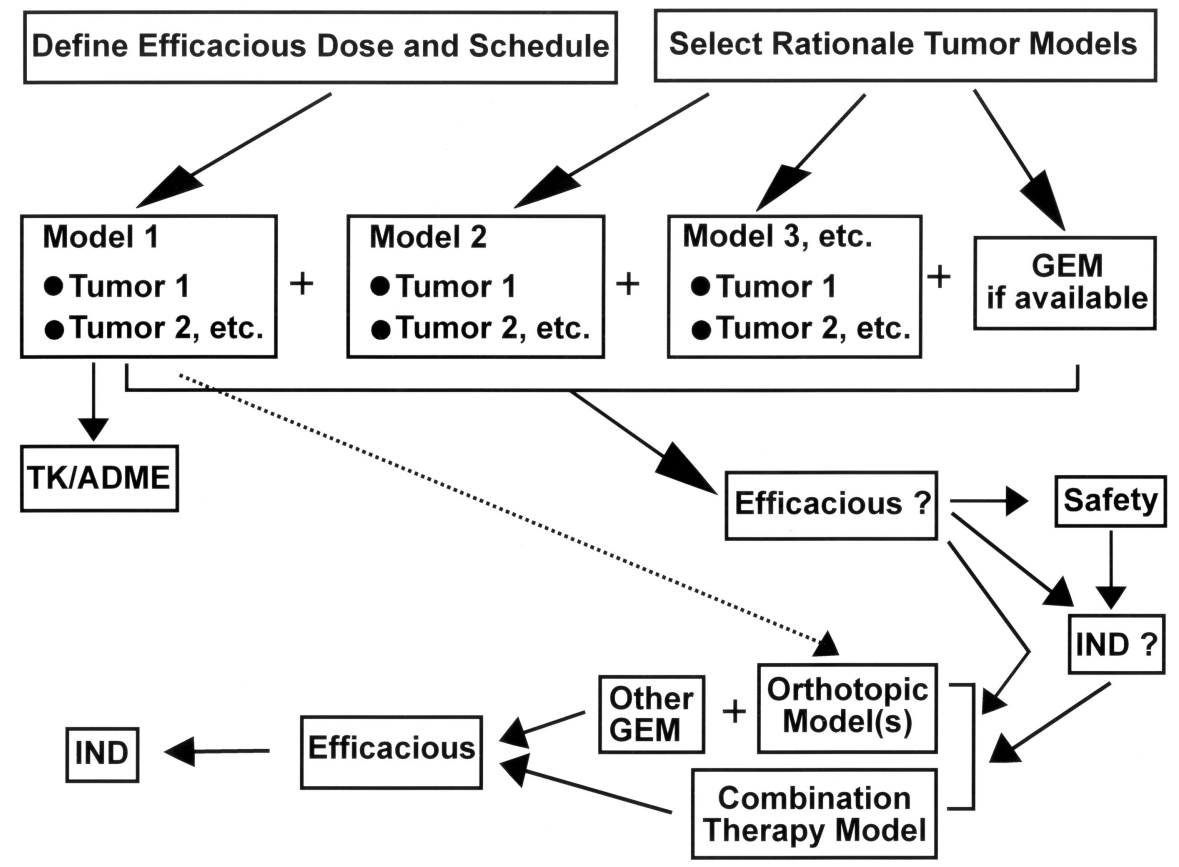

FIGURE 1.-A guide for preclinical efficacy testing of anti-tumor therapeutics. In addition to toxicokinetics (TK) and absorption, distribution, metabolism and excretion (ADME) studies, development programs should progress through an increasingly complex series of tumors in one or more mouse models, genetically engineered mice (GEM) and suitable models in other species. Once a probable level of efficacy is established by use of stringent endpoints in multiple models, an investigational new drug (IND) application may be feasible. Safety studies in tumor-bearing mice should be considered to evaluate toxicity during altered host homeostasis. If insufficient efficacy is established, additional studies utilizing orthotopic models, GEM and combination therapy models may be necessary to provide sufficient evidence of probable clinical efficacy. Well-characterized orthotopic and GEM models may be biologically superior to testing in other models and may provide a shortcut (dotted line) to demonstrating efficacy.

potential (target and predictivity for clinical success) between mice and humans (Siemann, 1987; Hann and Balmain, 2001; Balmain, 2002). Although a generic program is not advocated, in vivo preclinical efficacy programs for anti-tumor therapeutics should follow a guide for testing similar to that outlined in Figure 1. After selecting the appropriate dose and scheduling, an efficacy program most economically progresses from simple to more complex tumor model systems. Use of one or more simple models alone to determine possible clinical efficacy is contrary to the complexity and issues associated with tumor models in mice and the variation in accepted therapeutic protocols in clinical oncology. Utilizing multiple surrogate models (cells and explants, different stains of mice and/or additional species, different tumor stages), transplants using variants of the target tumor, and tumor testing in genetically altered animals begins to provide sufficient efficacy data that can support an IND application. This efficacy data should be accompanied by results from PK and ADME studies that evaluate kinetics in one or more tumor model systems. The IND application can also be strengthened by conducting safety studies in tumor-bearing animals as a model to mimic altered homeostasis in tumor-bearing humans.

Ideally, the IND should only be filed after completion of additional preclinical studies that match the genetic heterogeneity of human tumors (multiple animal and tumor models), at least partially match tumor prone genetic profiles in a tumor-bearing host (genetically altered animals), match tissue tropism (orthotopic models), and match the most accepted therapeutic protocols (combination therapy models). In some cases, the most appropriate models will be GEM or orthotopic models and a limited number of studies in standard mouse models are justified. Incorporation of multiple levels of efficacy testing along with careful selection of endpoints will lead to a development program that most closely matches molecular targets, therapeutic protocols and outcomes encountered in the clinic. Testing through all tiers may not be applicable or warranted and completion of all steps is not a guarantee of correlation with clinical efficacy. However, a thorough preclinical efficacy program provides greater assurance of potential therapeutic efficacy and safety than tumor modeling restricted to one or two implanted tumors in a single strain of mouse. The expense of comprehensive modeling and additional time spent in preclinical testing is modest compared to failure in phase II and phase III clinical trials.

\section{SUMMARY}

Transitions from in vitro to preclinical and then to clinical testing for tumor modulation remain difficult with a low rate of clinical entry for most therapeutic classes. Increased understanding of mechanisms of neoplasia through macromolecular biology, genomics and bioinformatics is helping to address treatment bottlenecks such as lack of specificity, low efficacy, toxicity and drug resistance, and helping to identify critical targets for clinical exploitation. In addition to cytotoxic, hormonal, adjunct, and medical device therapies, numerous novel strategies for enhanced and targeted drug deliver, anti-angiogenesis (inhibitors and enhanced 
permeation), immunotherapy (vaccines, monoclonal antibodies, toxin conjugates, prodrug activators, cytokine antagonists), small molecules (inhibitors of growth, matrix and adhesion), apoptosis (enhancers, inducers, proteasome inhibitors, reverse DNA methylation), anti-sense and gene therapy (tumor suppressor genes) and cell cycle alterations (inhibitors) are being developed for the anti-tumor market. However, our ability to model and accurately predict clinical efficacy is limited. Despite historical significance and ongoing utility, tumor models in mice used for preclinical therapeutic intervention often error towards false positive results and curing cancer in mice. The inadequacy of classic transplantation models for anti-tumor therapy is helping to drive development and use of new models based on genetic and technical modifications. However, underlying limitations of tumor models reinforce the need for careful attention to design (applying correct models to the question), conduct (using multiple models) and interpretation (recognizing limitations and applying stringent criteria to outcomes) of efficacy studies for tumor modulation. Animal models can provide quick answers but application of these results to predicting clinical outcomes is often undertaken prematurely. New strategies and techniques, and continued improvements in stringency and consistency of criteria used for evaluating outcomes will be necessary to ensure that tumor models in mice remain a useful tool for development of anticancer agents and devices.

\section{REFERENCES}

Abate-Shen, C., and Shen, M. M. (2002). Mouse models of prostate carcinogenesis. Trends Genet 18, S1-S5.

Alvarez, E. (2002). B16 murine melanoma: historical perspective on the development of a solid tumor model. Tumor Models in Cancer Research, Teicher B. A. Humana Press, Totowa, NJ.

An, Z., Jiang, P., Wang, X., Moossa, A. R., and Hoffman, R. M. (1999). Development of a high metastatic orthotopic model of human renal cell carcinoma in nude mice: benefits of fragment implantation compared to cellsuspension injection. Clin Exp Metastasis 17, 265-70.

Anderson, R. N. (2002). Deaths: leading causes for 2000. National Vital Statistics Report 50, 12-4.

Arias E., and Smith, B. L. (2003). Deaths: preliminary data for 2001. National Vital Statistics Report 51, 1-16.

Artandi, S. E. (2002). Telomore shortening and cell fates in mouse models of neoplasia. Trends Mol Med 8, 44-7.

Atassi, G., Dumont, P., Kabbe, H. J., and Yoder, O. (1988). A new antitumour agent, batracylin, selected by a preclinical solid tumour model. Drugs Exp Clin Res 14, 571-4.

Averbook, B., Schuh, J. C. L., Papay, R., and Maliszewski, C. (2002). Antitumor effects of flt 3 ligand in transplanted murine tumor models. J Immunother 25, 27-35.

Balmain, A. (2002). Cancer as a complex genetic trait: tumor susceptibility in humans and mouse models. Cell 108, 145-52.

Bankert, R. B., Egilmez, N. K., and Hess, S. D. (2001). Human-SCID mouse chimeric models for the evaluation of anti-cancer therapies. Trends Immunol 22, 386-93.

Bankert, R. B., Hess, S. D., and Egilmez, N. K. (2002). SCID mouse models to study human cancer pathogenesis and approaches to therapy: potential, limitations, and future directions. Front Biosci 7, 44-62.

Bardeesy, N., Sharpless, N. E., DePinho, R. A., and Merlino, G. (2001). The genetics of pancreatic adenocarcinoma: a roadmap for a mouse model. Semin Cancer Biol 11, 201-8.

Begemann, M., Fuller, G. N., and Holland, E. C. (2002). Genetic modeling of glioma formation in mice. Brain Pathol 12, 117-32.

Beltinger, C., and Debatin, K.-M. (2001). Murine models for experimental therapy of pediatric solid tumors with poor prognosis. Int J Cancer 92, 313-8.
Bernardi, R., Grisendi, S., and Pandolfi, P. P. (2002). Modelling haematopoietic malignancies in the mouse and therapeutical implications. Oncogene 21, 3445-58.

Berr, S. S., Roche, J. K., El-Rifai, W., Smith Jr., M. F., and Powell, S. M. (2003). Magnetic resonance imaging of gastric cancer in Tff1 knock-out mice. Magn Reson Med 49, 1033-6.

Bloomston, M., Zervos, E. E., and Rosemurgy II, A. S. (2002). Matrix metalloproteinases and their role in pancreatic cancer: a review of preclinical studies and clinical trials. Ann Surg Oncol 9, 668-74.

Bogden, A. E., Esber, H. J., Taylor, D. J., and Gray, J. H. (1974). Comparative study on the effects of surgery, chemotherapy, and immunotherapy, alone and in combination, on metastases of the 13762 mammary adenocarcinoma. Cancer Res 34, 1627-31.

Boivin, G. P., Washington, K., Yang, K., Ward, J. M., Pretlow, T. P., Russell, R., Besselsen, D. G., Godfrey, V. L., Doetschman, T., Dove, W. F., Pitot, H. C., Halberg, R. B., Itzkowitz, S. H., Groden, J., and Coffey, R. J. (2003). Pathology of mouse models of intestinal cancer: consensus report and recommendations. Gastroenterology 124, 762-7.

Bonfil, R. D., Russo, D. M., Binda, M. M., Delgado, F. M., and Vincenti, M. (2002). Higher antitumor activity of vinflunine than vinorelbine against an orthotopic murine model of transitional cell carcinoma of the bladder. Urol Oncol 7, 159-66.

Boone, C. W., Steele, V. E., and Kelloff, G. J. (1992). Screening for chemopreventive (anticarcinogenic) compounds in rodents. Mutat Res 267, 251-5.

Boyd, D. D., Kim, S. J., Wang, H., Jones, T. R., and Gallick, G. E. (2003). A urokinase-derived peptide (A6) increases survival of mice bearing orthotopically grown prostate cancer and reduces lymph node metastasis. Am J Pathol 162, 619 .

Burger, M. M. (2000). UICC study group on basic and clinical cancer research: animal models for the natural history of cancer. Int J Cancer 85, 303-5.

Burgos, J. S., Rosol, M., Moats, R. A., Khankaldyyan, V., Kohn, D. B., Nelson Jr., M. D., and Laug, W. E. (2003). Time course of bioluminescent signal in orthotopic and heterotopic brain tumors in nude mice. BioTechniques 34, 1184-8.

Cardiff, R. D. (2001). Validity of mouse mammary tumour models for human breast cancer: comparative pathology. Microsc Res Tech 52, 224-30.

Carson III, W. E., and Walker, M. J. (2002). Animal models of melanoma. Tumor Models in Cancer Research, Teicher B. A. Humana Press, Totowa, NJ.

Casas, A., Fukuda, H., Meiss, R., and Batlle, A. M. (1999). Topical and intratumoral photodynamic therapy with 5 -aminolevulinic acid in a subcutaneous murine mammary adenocarcinoma. Cancer Lett 141, 29-38.

Castillo, R., Diaz, J. W., Veloso, A., and Gavilondo, J. (1982). Leukemoid reaction induced by different transplantable tumors in three inbred mouse strains. Neoplasma 29, 73-9.

Chakrabarty, A., Hillman, G. G., Maughan, R. L., Visscher, D. W., Ali, E., Pontes, J. E., and Haas, G. P. (1994). Influence of tumor site on the therapy of murine kidney cancer. Anticancer Res 14, 373-8.

Chen, J. J. W., Peck, K., Hong, T.-M., Yang, S.-C., Sher, Y.-P., Shih, J.-Y., Wu, R., Cheng, J.-L., Roffler, S. R., Wu, C.-W., and Yang, P.-C. (2001). Global analysis of gene expression in invasion by a lung cancer model. Cancer Res 61, 5223-30.

Clarke, R. (2002). Human breast-cancer xenografts as models of the human disease. Tumor Models in Cancer Research, Teicher B. A. Humana Press, Totowa, NJ.

Corbett, T. H., Griswold Jr, D. P., Wolpert, M. K., Venditti, J. M., and Schabel Jr., F. M. (1979). Design and evaluation of combination chemotherapy trials in experimental animal tumor systems. Cancer Treat Rep 63, 799-801.

Corbett, T. H., Panchapor, C., Polin, L., Lowichik, N., Pugh, S., White, K., Kushner, J. Meyer, J., Czarnecki, J., Chinnukroh, S., Edelstein, M., LoRusso, P., Heilbrun, L., Horwitz, J. P., Grieshaber, C., Perni, R., Wentland, M., Coughlin, S., Elenbaas, S., Philion, R., and Rake, J. (1999). Preclinical efficacy of thioxanthone SR271425 against transplanted solid tumors of mouse and human origin. Invest New Drugs 17, 17-27.

Corbett, T. H., Polin, L., Roberts, B. J., Lawson, A. J., Leopold III, W. R., White, K., Kushner, J., Paluch, J., Hazeldine, S., Moore, R., Rake, 
J., and Horwitz, J. P. (2002). Transplantable syngeneic rodent tumors: solid tumors in mice. Tumor Models in Cancer Research, Teicher B. A. Humana Press, Totowa, NJ.

Couse, J. F., Davis, V. L., Hanson, R. B., Jefferson, W. N., McLachlan, J. A., Bullock, B. C., Newbold, R. R., and Korach, K. S. (1997). Accelerated onset of uterine tumors in transgenic mice with aberrant expression of the estrogen receptor after neonatal exposure to diethylstilbestrol. $\mathrm{Mol}$ Carcinog 19, 236-42.

Culp, L. A., Holleran, J. L., and Miller, C. J. (2001). Tracking prostate carcinoma micrometastasis to multiple organs using histochemical marker genes and novel cell systems. Histol Histopathol 16, 945-53.

Dellian, M., Witwer, B. P., Salehi, H. A., Yuan F., and Jain, R. K. (1996). Effect of basic fibroblast growth factor, vascular endothelial growth factor/vascular permeability factor, and host microenvironment. Am J Pathol 149, 59-71.

Dewhirst, M. W., Thrall, D., and MacEwen, E. G. (2002). Spontaneous pet animal cancers. Tumor Models in Cancer Research, Teicher B. A. Humana Press, Totowa, NJ.

Diament, M. J., Garcia, C., Stillitani, I., Saavedra, V. M., Manzur, T., Vauthay, L., and Klein, S. (1998). Spontaneous murine lung adenocarcinoma (P07): a new experimental model to study paraneoplastic syndromes of lung cancer. Int J Mol Med 2, 45-50.

Drexler, H. G., Dirks, W. G., Matsuo, Y., and MacLeod, R. A. (2003). False leukemia-lymphoma cell lines: an update on over 500 cell lines. Leukemia 17, 416-26.

Dvorak, H. F., Harvey, V. S., Estrella, P., Brown, L. F., McDonagh, J., and Dvorak, A. M. (1987). Fibrin containing gels induce angiogenesis. Implications for tumor stroma generation and wound healing. Lab Invest 57, 673-86.

Dykes, D. J., and Waud, W. R. (2002). Murine L1210 and P388 Leukemias. Tumor Models in Cancer Research, Teicher B. A. Humana Press, Totowa, NJ.

Eccles, S. A. (2002). Models for evaluation of targeted therapies of metastatic disease. Tumor Models in Cancer Research, Teicher B. A. Humana Press, Totowa, NJ.

Edinger, M., Sweeney, T. J., Tucker, A. A., Olomu, A. B., Negrin, R. S., and Contag, C. H. (1999). Noninvasive assessment of tumor cell proliferation in animal models. Neoplasia 1, 303-10.

Eto, M., Harada, M., Tamada, K., Tokuda, N., Koikawa, Y., Nakamura, M., Nomoto, K., and Naito, S. (2000). Antitumor activity of interleukin-12 against murine bladder cancer. $J$ Urol 163, 1549-52.

Fausto, N. (1999). Mouse liver tumorigenesis: models, mechanisms, and relevance to human disease. Semin Liver Dis 19, 243-52.

Feitelson, M. A., and Larkin, J. D. (2001). New animal models of hepatitis B and C. ILAR J 42, 127-38.

Fogh, J., Fogh, J. M., and Orfeo, T. (1977). One hundred and twenty-seven cultured human tumor cell lines producing tumors in nude mice. $J$ Natl Cancer Inst 59, 221-6.

Fu, X., Guadagni, F., and Hoffman, R. M. (1992). A metastatic nude-mouse model of human pancreatic cancer constructed orthotopically with histologically intact patient specimens. Proc Natl Acad Sci USA 89, 5645-9.

Furukawa, T., Kubota, T., Watanabe, M., Kitajima, M., and Hoffman, R. M. (1993a). A novel "patient-like" treatment model of human pancreatic cancer constructed using orthotopic transplantation of histologically intact human tumor tissue in nude mice. Cancer Res 53, 3070-2.

Furukawa, T., Kubota, T., Watanabe, M., Kuo, T. H., Kitajima, M., and Hoffman, R. M. (1993b). Differential chemosensitivity of local and metastatic human gastric cancer after orthotopic transplantation of histologically intact tumor tissue in nude mice. Int J Cancer 54, 397-401.

Gaudet, F., Hodgson, J. G., Eden, A., Jackson-Grusby, L., Dausman, J., Gray, J. W., Leonhardt, H., and Jaenisch, R. (2003). Induction of tumors in mice by genomic hypomethylation. Science $\mathbf{3 0 0}, 489$.

Gershwin, M. E., Ikeda, R. M., Kawakami, T. G., and Owens, R. B. (1977). Immunobiology of heterotransplanted human tumors in nude mice. $\mathrm{J} \mathrm{Natl}$ Cancer Inst 58, 1455-60.

Giard, D. J., Aaronson, S. A., Todaro, G. J., Arnstein, P., Kersey, J. H., Dosik, H., and Parks, W. P. (1973). In vitro cultivation of human tumors: establishment of cell lines derived from a series of solid tumors. J Natl Cancer Inst $\mathbf{5 1}$, 1417-23.
Giovanella, B. (2002). Xenotransplantation of human cell cultures in nude mice. Tumor Models in Cancer Research, Teicher B. A. Humana Press, Totowa, NJ.

Giraldi, T., Zorzet, S., Perissin, L., and Rapozzi, V. (2000). Stress and chemotherapy: combined effects on tumor progression and immunity in animal models. Ann NY Acad Sci 917, 549-59.

Goodman, J. I., and Watson, R. E. (2002). Altered DNA methylation: a secondary mechanism involved in carcinogenesis. Annu Rev Pharmacol Toxicol 42, 501-25.

Goytisolo, F. A., and Blasco, M. A. (2002). Many ways to telomere dysfunction: in vivo studies using mouse models. Oncogene 21, 584-91.

Granger, M. P., Wright, W. E., and Shay, J. W. (2002). Telomerase in cancer and aging. Crit Rev Oncol Hematol 41, 29-40.

Gunduz, N., Fisher, B., and Saffer, E. A. (1979). Effect of surgical removal on the growth and kinetics of residual tumor. Cancer Res 39, 3861-5.

Gutmann, D. H., Baker, S. J., Giovannini, M., Garbow, J., and Weiss, W. (2003). Mouse models of human cancer consortium symposium on nervous system tumors. Cancer Res 63, 3001-4.

Hann, B., and Balmain, A. (2001). Building 'validated' mouse models of human cancer. Curr Opin Cell Biol 13, 778-84.

Harrison, S. (2002). Perspective on the history of tumor models. Tumor Models in Cancer Research, Teicher B. A. Humana Press, Totowa, NJ.

Hay, R. J. (1991). Operator-induced contamination in cell culture systems. Dev Biol Stand 75, 193-204.

Herber, R., Liem, A., Pitot, H., and Lambert, P. F. (1996). Squamous epithelial hyperplasia and carcinoma in mice transgenic for the human papillomavirus type 16 E7 oncogene. J Virol 70, 1873-81.

Herzig, M., and Christofori, G. (2002). Recent advances in cancer research: mouse models of tumorigenesis. Biochim Biophys Acta 1602, 97-113.

Heyer, J., Yang, K., Lipkin, M., Edelmann, W., and Kucherlapati, R. (1999). Mouse models for colorectal cancer. Oncogene 18, 5325-33.

Hillman, G. G. (2002). Experimental animal models for renal cell carcinoma. Tumor Models in Cancer Research, Teicher B. A. Humana Press, Totowa, NJ.

Hoffman, R. M. (1999). Orthotopic metastatic mouse models for anticancer drug discovery and evaluation: a bridge to the clinic. Invest New Drugs 174, 343-59.

Hoffman, R. M. (2002). Green fluorescent protein imaging of tumour growth, metastasis, and angiogenesis in mouse models. Oncology 3, 546-56.

Holland, E. C. (2001). Brain tumor animal models: importance and progress. Curr Opin Oncol13, 143-7.

Hoon, D. S., Fujimoto, A., Shu, S., and Taback, B. (2002). Assessment of genetic heterogeneity in tumors using laser capture microdissection. Meth Enzymol 356, 302-9.

Horig, H., Wainstein, A., Long, L., Kahn, D., Soni, S., Marcus, A., Edelmann, Kucherlapati, W. R., and Kaufman, H. L. (2001). A new mouse model for evaluating the immunotherapy of human colorectal cancer. Cancer Res $\mathbf{6 1}$, 8520 .

Hotz, H. G., Hines, O. J., Foitzik, T., and Reber, H. A. (2000). Animal models of exocrine pancreatic cancer. Int J Colorectal Dis 15, 136-43.

Houghton, P. J., Adamson, P. C., Blaney, S., Fine, H. A., Gorlick, R., Haber, M., Helman, L., Hirschfeld, S., Hollingshead, M. G., Israel, M. A., Lock, R. B., Maris, J. M., Merlino, G., Patterson, W., Reynolds, C. P., Shannon, K., Yu, A., Yu, J., and Smith, M. A. (2002). Testing of new agents in childhood cancer preclinical models: meeting summary. Clin Cancer Res $\mathbf{8}$, 3646-57.

Hursting, S. D. (1997). Experimental models of gene-environment interaction for cancer chemoprevention studies. Curr Opin Oncol 9, 487-91.

Huseby, R. A. (1969). Utility and failure of models in oncology. Fed Proc 28, $211-5$.

Hutchinson, J. N., and Muller, W. J. (2000). Transgenic mouse models of human breast cancer. Oncogene 19, 6130-7.

Jackson-Grusby, L. (2002). Modeling cancer in mice. Oncogene 21, 5504-14.

Jain, R. K., Munn, J. J., and Fukumura, D. (2002). Transparent window models and intravital microscopy: imagine gene expression, physiological function, and drug delivery in tumors. Tumor Models in Cancer Research, Teicher B. A. Humana Press, Totowa, NJ. 
Jonkers, J., and Berns, A. (2002). Conditional mouse models of sporadic cancer. Nat Rev Cancer 2, 251-65.

Justice, M. J., Noveroske, J. K., Weber, J. S., Zheng, B., and Bradley, A. (1999). Mouse ENU mutagenesis. Hum Mol Genet 8, 1955.

Kennel, S. J., Lankford, T., Davern, S., Foote, L., Taniguchi, K., Ohizumi, I., Tsutsumi, Y., Nakagawa, S., Mayumi, T., and Mirzadeh, S. (2002). Therapy of rat tracheal carcinoma IC-12 in SCID mice: vascular targeting with [213Bi]-MAb TES-23. Eur J Cancer 38, 1278-87.

Kerbel, R. S. (1999). What is the optimal rodent model for anti-tumor drug testing? Cancer Metastasis Rev 17, 301-4.

Keshavarzi, A., Vaezy, S., Noble, M. L., Chi, E. Y., Walker, C., Martin, R. W., and Fujimoto, V. Y. (2002). Treatment of uterine leiomyosarcoma in a xenograft nude mouse model using high-intensity focused ultrasound: a potential treatment modality for recurrent pelvic disease. Gynecol Oncol 86, 344-50.

Killion, J. J., Radinsky, R., and Fidler, I. J. (1999). Orthotopic models are necessary to predict therapy of transplantable tumors in mice. Cancer Metastasis $\operatorname{Rev} 17,284$.

Klatt, P., and Serrano, M. (2003). Engineering cancer resistance in mice. Carcinogenesis $\mathbf{2 4}, 817$.

Klausner, R. D. (1999). Studying cancer in the mouse. Oncogene 18, 5249-52.

Knapp, D. W., and Waters, D. J. (1997). Naturally occurring cancer in pet dogs: important models for developing improved cancer therapy for humans. Mol Med Today 3, 8-11.

Kobaek-Larsen, M., Thorup, I., Diederichsen, A., Fenger, C., and Hoitinga, M. R. (2000). Review of colorectal cancer and its metastases in rodent models: comparative aspects with those in humans. Comp Med 50, 16-26.

Koike, K. (2002). Hepatocarcinogenesis in hepatitis viral infection: lessons from transgenic mouse studies. J Gastroenterol 37, 55-64.

Kristjansen, P. E. G. (2002). Tissue-isolated tumors in mice: ex vivo perfusion of human tumor xenografts. Tumor Models in Cancer Research, Teicher B. A. Humana Press, Totowa, NJ.

Kruger, A., Schirrmacher, V., and Khokha, R. (1999). The bacterial lacZ gene: an important tool for metastasis research and evaluation of new cancer therapies. Cancer Metastasis Rev 17, 285-94.

Kunstfeld, R., Wickenhauser, G., Michaelis, U., Teifel, M., Umek, W., Naujoks, K., Wolff, K., and Petzelbauer, P. (2003). Paclitaxel encapsulated in cationic liposomes diminishes tumor angiogenesis and melanoma growth in a "humanized" SCID mouse model. J Invest Dermatol 120, 476-82.

Kuo, T.-H., Kubota, T., Watanabe, M., Furukawa, T., Kase, S., Tanino, H., Saikawa, Y., Ishibiki, K., Kitajima, M., and Hoffman, R. M. (1993). Sitespecific chemosensitivity of human small-cell lung carcinoma growing orthotopically compared to subcutaneously in SCID mice: the importance of orthotopic models to obtain relevant drug evaluation data. Anticancer Res 13, 627-30.

Lapidot, T., Fajerman, Y., and Kollet, O. (1997). Immune-deficient SCID and NOD/SCID mice models as functional assays for studying normal and malignant human hematopoiesis. $J$ Mol Med 75, 664-73.

Laster Jr., W. R., Schabel Jr, F. M., Skipper, H. E., Wilcox, W. S., and Thomson, J. R. (1961). Experimental evaluation of potential anticancer agents IV. host weight loss as it relates to false positives in drug evaluation. Cancer Res 21, 895-906.

Li, C. Y., Shan, S., Huang, Q., Braun, R. D., Lanzen, J., Hu, K., Lin, P., and Dewhirst, M. W. (2000). Initial stages of tumor cell-induced angiogenesis: evaluation via skin window chambers in rodent models. J Natl Cancer Inst 92, 143-7.

Liebelt, R. A., Gehring, G., Delmonte, L., Schuster, G., and Liebelt, A. G. (1974). Paraneoplastic syndromes in experimental animal model systems. Ann NY Acad Sci 230, 547-64.

Lin, J., Sahakian, D. C., de Morais, S. M., Xu, J. J., Polzer, R. J., and Winter, S. M. (2003). The role of absorption, distribution, metabolism, excretion and toxicity in drug discovery. Curr Top Med Chem 3, 1125-4.

Liu, J., and Johnston, M. R. (2002). Animal models for studying lung cancer and evaluating novel intervention strategies. Surg Oncol 11, 217-27.

Maierhofer, C., Gangnus, R., Diebold, J., and Speicher, M. R. (2003). Multicolor deconvolution microscopy of thick biological specimens. Am J Pathol 162, 373.
Malkinson, A. M. (2001). Primary lung tumors in mice as an aid for understanding, preventing, and treating human adenocarcinoma of the lung. Lung Cancer 32, 265-79.

Manivasager, V., Heng, P. W., Hao, J., Zheng, W., Soo, K. C., and Olivo, M. (2002). Macro-microscopic fluorescence imaging of human NPC xenografts in a murine model using topical vs intravenous administration of 5-aminolevulinic acid. Int J Oncol 21, 1003-7.

Manzotti, C., Audisio, R. A., and Pratesi, G. (1993). Importance of orthotopic implantation for human tumors as model systems: relevance to metastasis and invasion. Clin Exp Metastasis 11, 5-14.

McClatchey A. I. (1999). Modeling metastasis in the mouse. Oncogene 18 , 5334-9.

Menon, K., and Teicher, B. A. (2002). Metastasis models: lungs, spleen/liver, bone, and brain. Tumor Models in Cancer Research, Teicher B. A. Humana Press, Totowa, NJ.

Meuwissen, R., Jonkers J., and Berns, A. (2001). Mouse models for sporadic cancer. Exp Cell Res 264, 100-10.

Mickisch, G. H., Merlino, G. T., Galski, H., Gottesman, M. M., and Pastan, I. (1991). Transgenic mice that express the human multidrug-resistance gene in bone marrow enable a rapid identification of agents that reverse drug resistance. Proc Natl Acad Sci USA 88, 547-51.

Monsky, W. L., Carreira, C. M., Tsuzuki, Y., Gohongi, T., Fukumura, D., and Jain, R. K. (2002). Role of host microenvironment in angiogenesis and microvascular functions in human breast cancer xenografts: mammary fat pad versus cranial tumors. Clin Cancer Res 8, 1008-13.

Moore, K. J., and Nagle, D. L. (2000). Complex trait analysis in the mouse: the strengths, the limitations and the promise yet to come. Annu Rev Genet 34, 653-86.

Moseley, G. W., Elliott, J., Wright, M. D., Partridge, L. J., and Monk, P. N. (2003). Interspecies contamination of the KM3 cell line: implications for CD63 function in melanoma metastasis. Int $J$ Cancer $\mathbf{1 0 5}$, 613-6.

Mukherjee, P., El-Abbadi, M. M., Kasperzyk, J. L., Ranes, M. K., and Seyfried, T. N. (2002). Dietary restriction reduced angiogenesis and growth in an orthotopic mouse brain tumour model. Br J Cancer 86, 1615-21.

Myers, J. N., Holsinger, F. C., Jasser, S. A., Bekele, B. N., and Fidler, I. J. (2002). An orthotopic nude mouse model of oral tongue squamous cell carcinoma. Clin Cancer Res 8, 293-8.

Naf, D., Krupke, D. M., Sundberg, J. P., Eppig, J. T., and Bult, C. J. (2002). The mouse tumor biology database: a public resource for cancer genetics and pathology of the mouse. Cancer Res 62, 1235.

Naito, S., Giavazzi, R., Walker, S. M., Itoh, K., Mayo, J., and Fidler, I. J. (1987a). Growth and metastatic behavior of human tumor cells implanted into nude and beige nude mice. Clin Exp Metastasis 5, 135-46.

Naito, S., von Eschenback, A. C., and Fidler, I. J. (1987b). Different growth pattern and biologic behavior of human renal cell carcinoma implanted into different organs of nude mice. J Natl Cancer Inst 78, 377-85.

Navone, N. M., Logothetis, C. J., von Eschenbach, A. C., and Troncoso, P. (1999). Model systems of prostate cancer: uses and limitations. Cancer Metastasis Rev 17, 361-71.

Nelson, A. L., Algon, S. A., Munasinghe, J., Graves, O., Goumnerova, L., Burstein, D., Pomeroy, S. L., and Kim, J. Y. (2003). Magnetic resonance imaging of patched heterozygous and xenografted mouse brain tumors. $J$ Neurooncol 62, 259-67.

Nicklas, W., Kraft, V., and Meyer, B. (1993). Contamination of transplantable tumors, cell lines, and monoclonal antibodies with rodent viruses. $L a b$ Anim Sci 43, 296-300.

Nyska, A., Dayan, A., and Maronpot, R. R. (2002). New tools in therapeutic research-prostatic cancer and models. Toxicol Pathol 30, 283-7.

Opitz, O. G., Harada, H., Suliman, Y., Rhoades, B., Sharpless, N. E., Kent, R., Kopelovich, L., Nakagawa, H., and Rustgi, A. K. (2002). A mouse model of human oral-esophageal cancer. J Clin Invest 110, 761.

Orsulic, S., Li, Y., Soslow, R. A., Vitale-Cross, L. A., Gutkind, J. S., and Varmus, H. E. (2002). Induction of ovarian cancer by defined multiple genetic changes in a mouse model system. Cancer Cell 1, 53-62.

Paddock, S. W. (1999). Confocal laser scanning microscopy. BioTechniques 27, 992-1004. 
Pettaway, C. A., Pathak, S., Greene, G., Ramirez, E., Wilson, M. R., Killion, J. J., and Fidler, I. J. (1996). Selection of highly metastatic variants of different human prostatic carcinomas using orthotopic inplantation in nude mice. Clin Cancer Res 2, 1627-36.

Pitot, H. C. (2001). Animal models of neoplastic development. Develop Biol 106, 53-7.

Rahman, N. A., and Huhtaniemi, I. T. (2001). Ovarian tumorigenesis in mice transgenic for murine inhibin alpha subunit promoter-driven Simian Virus $40 \mathrm{~T}$-antigen ontogeny, functional characteristics, and endocrine effects. Biol Reprod 64, 1122-30.

Rahman, N. A., Kananen Rilianawati, K., Paukku, T., Mikola, M., Markkula, M., Hamalainen, T., and Huhtaniemi, I. T. (1998). Transgenic mouse models for gonadal tumorigenesis. Mol Cell Endocrinol 145, 167-74.

Ray, P., Wu, A. M., and Gambhir, S. S. (2003). Optical bioluminescence and positron emission tomography imaging of a novel fusion reporter gene in tumor xenografts of living mice. Cancer Res 63, 1160-5.

Reilly, K. M., and Jacks, T. (2001). Genetically engineered mouse models of astrocytoma: GEMs in the rough? Semin Cancer Biol 11, 177-91.

Resor, L., Bowen, T. J., and Wynshaw-Boris, A. (2001). Unraveling human cancer in the mouse: recent refinements to modeling and analysis. Hum Mol Genet 10, 669-75.

Rew, D. A. (2000a). Modelling in tumour biology part I: modelling concepts and structures. Eur J Surg Oncol 26, 78-94.

Rew, D. A. (2000b). Modelling in tumour biology part II: modelling cancer therapy. Eur J Surg Oncol 26, 181-8.

Rideout III, W. M., Wakayama, T., Wutz, A., Eggan, K., Jackson-Grusby, L., Dausman, J., Yanagimachi, R., and Jaenisch, R. (2000). Generation of mice from wild-type and targeted ES cells by nuclear cloning. Nat Genet 24, 109-10.

Righi, L., Deaglio, S., Pecchioni, C., Gregorini, A., Horenstein, A. L., Bussolati, G., Sapino, A., and Malavasi, F. (2003). Role of CD31/platelet endothelial cell adhesion molecule-1 expression in in vitro and in vivo growth and differentiation of human breast cancer cells. Am J Pathol 162, 1163.

Rosenberg, E., Holmes, M., Tenenholz, T., Khalil, A. E. R., and Valerie, K. (2003). Preservation of fluorescent protein activity in tumor tissue. BioTechniques 34, 476-80.

Rosenberg, M. P., and Bortner, D. (1999). Why transgenic and knockout animal models should be used (for drug efficacy studies in cancer). Cancer Metastasis Rev 17, 295-9.

Rosner, A., Miyoshi, K., Landesman-Bollag, E., Xu, X., Seldin, D. C., Moser, A. R., MacLeod, C. L., Shyamala, G., Gillgrass, A. E., and Cardiff, R. D. (2002). Pathway pathology: histological differences between ErbB/Ras and wnt pathway transgenic mammary tumors. Am J Pathol 161, 1087.

Royal, R., Lange, P. H., and Vessella, R. (1996). Preclinical models of prostate cancer. Semin Oncol 23, 35-40.

Ruggero, D., Grisendi, S., Piazza, F., Rego, E., Mari, F., Rao, P. H., CordonCardo, C., and Pandolfi, P. P. (2003). Dyskeratosis congenita and cancer in mice deficient in ribosomal RNA modification. Science 299, 259.

Sadar, M. D., Akopian, V. A., and Beraldi, E. (2002). Characterization of a new in vivo hollow fiber model for the study of progression of prostate cancer to androgen independence. Mol Cancer Ther 1, 629-37.

Schipper, H., Goh, C. R., and Wang, T. L. (1995). Shifting the cancer paradigm: must we kill to cure? J Clin Oncol 801-7.

Schwartz, J., and Gu, X. (2002). Hamster oral cancer model. Tumor Models in Cancer Research, Teicher B. A., Humana Press, Totowa, NJ.

Seki, N., Hayakawa, Y., Brooks, A. D., Wine, J., Wiltrout, R. H., Yagita, H., Tanner, J. E., Smyth M. J., and Sayers, T. J. (2003). Tumor necrosis factorrelated apoptosis-inducing ligant-mediated apoptosis is an important endogenous mechanism for resistance to liver metastases in murine renal cancer. Cancer Res 63, 207-13.

Sharma, P., and Schreiber-Agus, N. (1999). Mouse models of prostate cancer. Oncogene 18, 5349-55.

Siemann, D. W. (1987). Satisfactory and unsatisfactory tumor models factors influencing the selection of a tumor model for experimental evaluation. Rodent Tumor Models in Experimental Cancer Therapy, Kallman, R. F., Pergamon Books, Inc, Elmsford, NY.
Skipper, H. E. (1968). Biochemical, biological, pharmacologic, toxicologic, kinetic, and clinical (subhuman and human) relationships. Cancer 21, 60010 .

Skipper, H. E. (1990). Tumor differences, drug differences, treatment design differences, and effects on therapeutic outcome (degree and duration of therapeutic response). Prog Clin Biol Res 354, 81-98.

Spitsbergen, J. M., and Kent, M. L. (2003). The state of the art of the zebrafish model for toxicology and toxicologic pathology research—advantages and current limitations. Toxicol Pathol 31, 62-87.

Standop, J., Schneider, M. B., Ulrich, A., and Pour, P. M. (2001). Experimental animal models in pancreatic carcinogenesis: lessons for human pancreatic cancer. Dig Dis 19, 24-31.

Steel, G. G. (1987). How well do xenografts maintain the therapeutic response characteristics of the source tumor in the donor patient? Rodent Tumor Models in Experimental Cancer Therapy, Kallman, R. F., Pergamon Books, Inc, Elmsford, NY.

Strandberg, J. D. (2000). Comparative pathology of benign prostatic hyperplasia. Prostatic Diseases, Lepor, H. WB Saunders Co., Philadelphia, PA.

Suttie, A., Nyska, A., Haseman, J. K., Moser, G. J., Hackett, T. R., and Goldsworthy, T. L. (2003). A grading scheme for the assessment of proliferative lesions of the mouse prostate in the TRAMP model. Toxicol Pathol 31, 31-38.

Tanaka, R., Okada, M., Kajimura, N., Otsubo, K., Gyotoku, M., Nagasaki, K., Ekimoto, H., and Yamaguchi, K. (1996). Triple paraneoplastic syndrome of hypercalcemia, leukocytosis and cachexia in two human tumor xenografts in nude mice. Jpn J Clin Oncol 26, 88-94.

Teicher, B. A. (1997). Models for minimal residual tumor. Anticancer Drug Development Guide: Preclinical Screening, Clinical Trials, and Approval. Teicher, B. A. Humana Press Inc., Totowa, NJ.

Teicher, B. A. (2002). In vivo tumor response end points. Tumor Models in Cancer Research. Teicher, B. A. Humana Press, Totowa, NJ.

Thompson, H. J., and Sporn, M. B. (2002). Mammary cancer in rats. Tumor Models in Cancer Research, Teicher, B. A., Humana Press, Totowa, NJ.

Trainer, D. L., Kline, T., McCabe, F. L., Faucette, L. F., Feild, J., Chaikin, M., Anzano, M., Rieman, D., Hoffstein, S., Li, D.-J., Gennaro, D., Buscarino, C., Lynch, M., Poste, G., and Greig, R. (1988). Biological characterization and oncogene expression in human colorectal carcinoma cell lines. Int $J$ Cancer 41, 287-96.

Tuveson, D. A., and Jacks, T. (1999). Modeling human lung cancer in mice: similarities and shortcomings. Oncogene 18, 5318-24.

Tuveson, D. A., and Jacks, T. (2002). Technologically advanced cancer modeling in mice. Curr Opin Genet Dev 12, 105-10.

Uckun, F. M., and Sensel, M. G. (2002). SCID mouse models of human leukemia and lymphoma as tools for new agent development. Tumor Models in Cancer Research, Teicher B. A., Humana Press, Totowa, NJ.

UKCCCR. (1998). United kingdom coordinating committee on cancer research (UKCCCR) guidelines for the welfare of animals in experimental neoplasia (second edition). Br J Cancer 77, 1-10.

Vail, D. M., and MacEwen, E. G. (1997). Spontaneously occurring tumors in companion animals as models for drug development. Anticancer Drug Development Guide: Preclinical Screening, Clinical Trials, and Approval, Teicher, B. A., Humana Press, Totowa, NJ.

van Dyke, T., and Jacks, T. (2002). Cancer modeling in the modern era: progress and challenges. Cell 108, 135-44.

Vanchieri, C. (2001). Move over, mouse: make way for the woodchucks, ferrets, and zebrafish. J Natl Cancer Inst 93, 418-9.

Vanderkerken, K., De Leenheer, E., Shipman, C., Asosingh, K., Willems, A., van Camp, B., and Croucher, P. (2003). Recombinant osteoprotegerin decreases tumor burden and increases survival in a murine model of multiple myeloma. Cancer Res 63, 287-9.

Wallace, J. (2000). Humane endpoints and cancer research. ILAR J 41, 87-93.

Waters, D. J., and Bostwick, D. G. (1997). The canine prostate is a spontaneous model of intraepithelial neoplasia and prostate cancer progression. Anticancer Res 17, 1467-70.

Waters, D. J., Bostwick, D. G., and Murphy, G. P. (1998). Conference summary: first international workshop on animal models of prostate cancer. Prostate 36, 47-48. 
Watson, A., Wu, X., and Bruchez, M. (2003). Lighting up cells with quantum dots. BioTechniques 34, 296-303.

Wetterwald, A., van der Pluijm, G., Que, I., Sijmons, B., Buijs, J., Karperien, M., Lowik, C. W. G. M., Gautschi, E., Thalmann, G. N., and Cecchini, M. G. (2002). Optical imaging of cancer metastasis to bone marrow: a mouse model of minimal residual disease. Am J Pathol 160, 1143.

Wheeler, D. L., Church, D. M., Federhen, S., Lash, A. E., Madden, T. L., Pontius, J. U., Schuler, G. D., Schriml, L. M., Sequeira, E., Tatusova, T. A., and Wagner, L. (2003). Database resources of the national center for biotechnology. Nucleic Acids Res 31, 28-33.

Wichmann, M. W., Muller, C., Meyer, G., Adam, M., Angele, M. K., Eisenmenger S. J., and Schildberg, F. W. (2003). Different immune responses to abdominal surgery in men and women. Langenbeck's Arch Surg 387, 397-401.

Wilmanns, C., Fan, D., O’Brian, C. A., Bucana, C. D., and Fidler, I. J. (1992). Orthotopic and ectopic organ environments differently influence the sensitivity of murine colon carcinoma cells to doxorubicin and 5-fluorouracil. Int J Cancer 52, 78-104.
Yang, H., Berger, F., Tran, C., Gambhir, S. S., and Sawyers, C. L. (2003). MicroPET imaging of prostate cancer in LNCAP-SR39TK-GFP mouse xenografts. Prostate 55, 39-47.

Yoneda, T., Aufdemorte, T. B., Nishimura, R., Nishikawa, N., Sakuda, M., Alsina, M. M., Chavez, J. B., and Mundy, G. R. (1991). Occurrence of hypercalcemia and leukocytosis with cachexia in a human squamous cell carcinoma of the maxilla in athymic nude mice: a novel experimental model of three concomitant paraneoplastic syndromes. J Clin Oncol 9, $468-77$.

Zan, Y., Haag, J. D., Chen, K. S., Shepel, L. A., Wigington, D., Wang, Y. R., Hu, R., Lopez-Guajardo, C. C., Brose, H. L., Porter, K. I., Leonard, R. A., Hitt, A. A., Schommer, S. L., Elegbede, A. F., and Gould, M. N. (2003). Production of knockout rats using ENU mutagenesis and a yeast-based screening assay. Nat Biotechnol 21, 645-51.

Zhang, Z., Yin, L., Zhang, Y., and Zhao, F. (2002). In situ transduction of cytosine deaminase gene followed by systemic use of 5-fluorocytosine inhibits tumor growth and metastasis in orthotopic prostate cancer mouse models. Chin Med J 115, 227-31. 